\title{
Electron Microscopic study of Desmosomes and Tonofilaments in Lichen Planus
}

\author{
Sawsan Khalifa EL- Sayed* and Hossam El- Dein Hussin Osman **. \\ From Department of Dermatology and Venereology, \\ Al- Azhar University for Girl, Cairo and Anatomy Department, \\ Al- Azhar University for Boys, Cairo **.
}

\begin{abstract}
:
Introduction: Lichen planus (L.P) is an idiopathic inflammatory disease of the skin and mucous membrane.

Desmosomes are responsible for the adhesion of keratinocytes. Tonofilaments are one of the major cytoskeleton structure in mammalian epidermis.

Patients and Methods: Six patients complained from Lichen planus are included in this study for the study of ultrastructure of both desmosomes \& tonofilaments .

Results: revealed an increase in the size and numbers of both of them which can be explained as a one of the defensive mechanism of the cells against frequent rubbing which is accompanied L.P. which is considered as a resistance mechanism of keratinocytes.
\end{abstract}

\section{Introduction}

Lichen planus is an idiopathic inflammatory disease of the skin \& mucous membrane. It is characterized by pruritic violaceous papules that favor the extremities (Boyd and Neldner, 1991).

Although its etiology and pathogenesis are not fully understood, L.P has been associated with multiple disease process and agents, such as viral infections, autoimmune disease, medications, vaccinations and dental restorative material (Shiohara and Kana, 2003).

Desmosomes are the major adhesion complex in epidermis anchoring keratin intermediate filaments to the cell membrane \& bridging adjacent keratinocytes and allowing cells to withstand trauma (Nickoloff et al., 2002). Desmosomes serve in maintain cellular integrity and they are also postulated to have a function in transducing signals (Cowin and Burre, 1996).

Tonofilaments are a complex of network of bundles of cytoplasmic keratin filaments which link both desmosomes \& hemidesmosomes. Tonofilaments appear to form an elaborate network of guyropes which distribute mechanical forces evently throughout the epidermis. These bundles are so coarse in case of skin that can be seen by light microscope (Carr and Tover, 1982).

\section{Patients and Methods}

Six patients examined clinically \& pathologically (by $H \& E$ ) \& proved to have lichen planus are involved in this study from the period of 12/ 2005 up to 3/ 2006 from out patient clinic of dermatology \& Venereology department of El Zahraa hospital. Detailed history of the disease was taken from the patients \& then sent speciemens to the Electron microscopy unit in anatomy department in $\mathrm{Al}$ Azhar faculty of medicine (Boy branch, Cairo) for preparation to be examined by Electron microscopy.

Steps used for the preparation of specimen were:

\section{1- Obtaining materials:}

Punch biopsy was used in our study after injection of the lesion with lidocain $\mathrm{Hcl}$ as a local anesthesia.

\section{2- Fixation:}

The specimens fixed using double procedures with the following steps: 


\section{Sawsan Khalifa EL- Sayed \& Hossam El- Dein Hussin Osman.}

A- glutaraldhyde fixative

- glutaraldhyde $25 \%$

-Buffer

$5 \mathrm{ml}$

-Distilled water

$15 \mathrm{ml}$

$20 \mathrm{ml}$

B- Washing specimens after first fixation using cacdhlate buffer.

C- Second fixation by osmium tetroxide

- Osmimum tetroxide $\quad 1 \mathrm{gm}$

- Buffer solution $\quad 40 \mathrm{ml}$

- Distilled water $\quad 60 \mathrm{ml}$

\section{3- Dehydration:}

- Tissue piece are washed twice in buffer for $30 \mathrm{~min}$.

- Dehydration of specimen in ascending grades of ethanol from 50\% up to $100 \%$.

- Complete the dehydration of specimens with propylene oxide.

\section{4- Embedding:}

Water soluble resins are used for embedding specimens.

\section{5- Sectioning:}

It is always worth while cutting thick (1- 2 Um) section of the whole face of the block. These are staining rapidly with toloudine blue.

\section{6- Staining:}

The section is first mounted in support girds and then the gird floated face down in the staining solution. The section were mounted in non coated girds, stained with $2 \%$ uranyl acetate for 15 minutes and lead citrate for $3 \mathrm{~min}$ and examined under the transmission E.M.

\section{Results}

After examination of the specimen prepared for E.M all the six cases of lichen planus showed increase in the size and number of both tonofilaments \& desmosomes. Some of the specimen showed marked increase in the cytoskeletal apparatus of the cells. In some specimen tonofilaments fills more than $1 / 3$ of the cytoplasm.

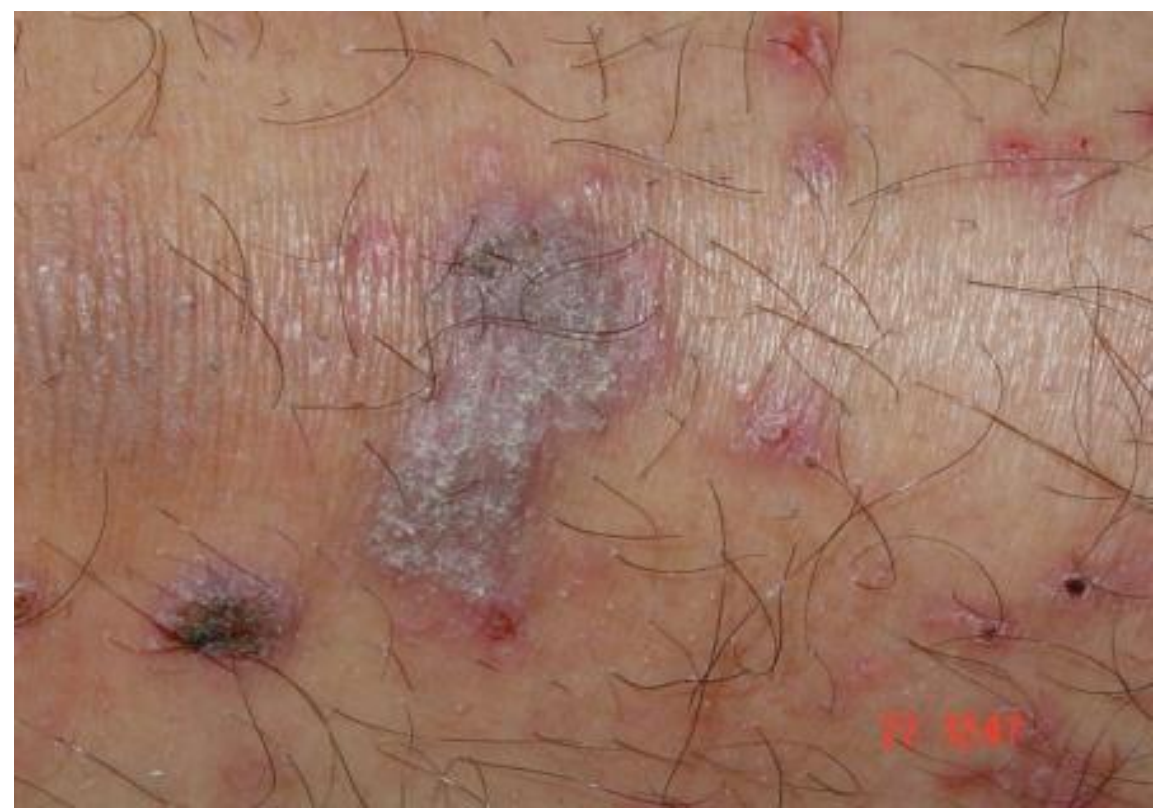

Figure 1: A case of lichen planus. 


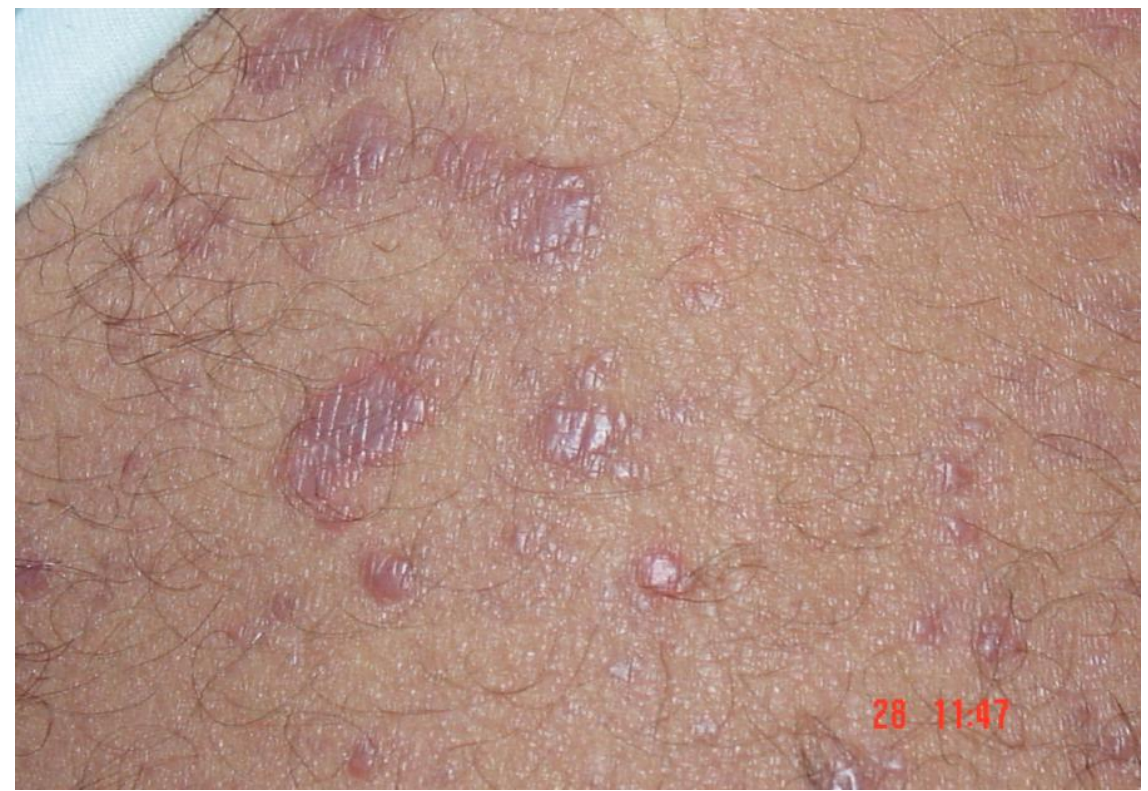

Figure 2: Another case of lichen planus.

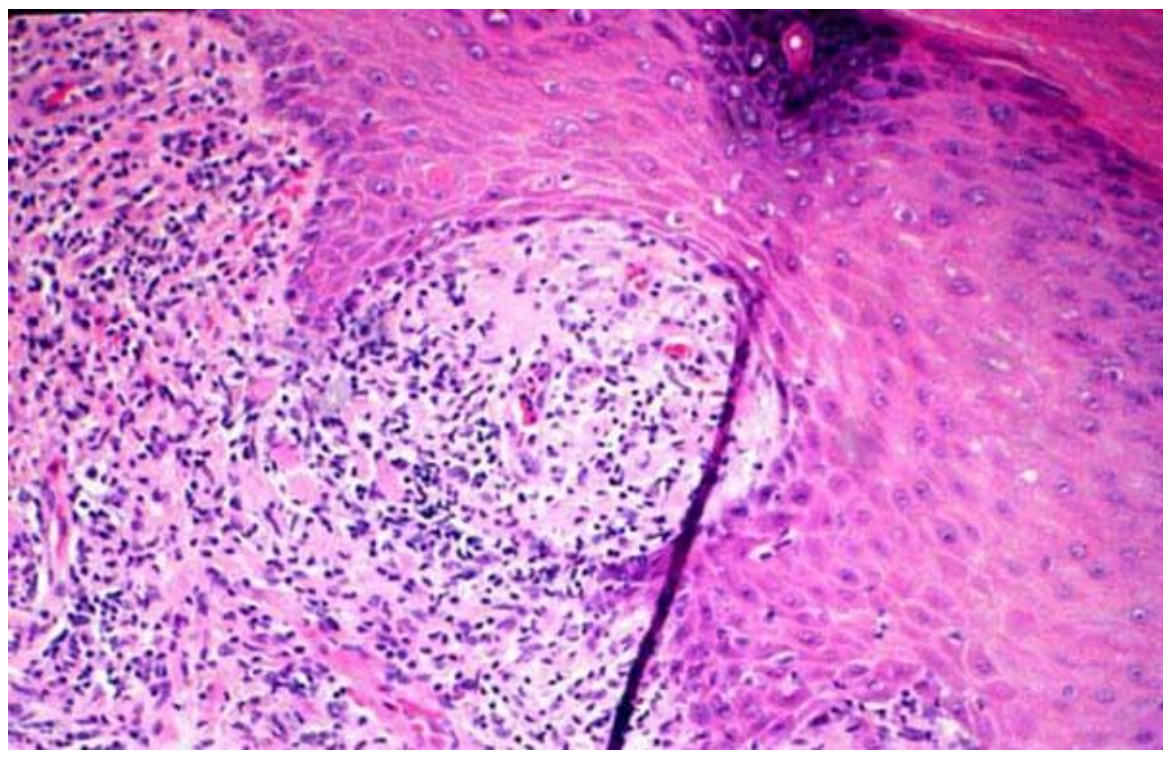

Figure 3: Histopathology of a case of lichen planus.

Histopathologic features of lichen planus. Hyperkeratosis focal increase in granular and lichenoid infillrate. 


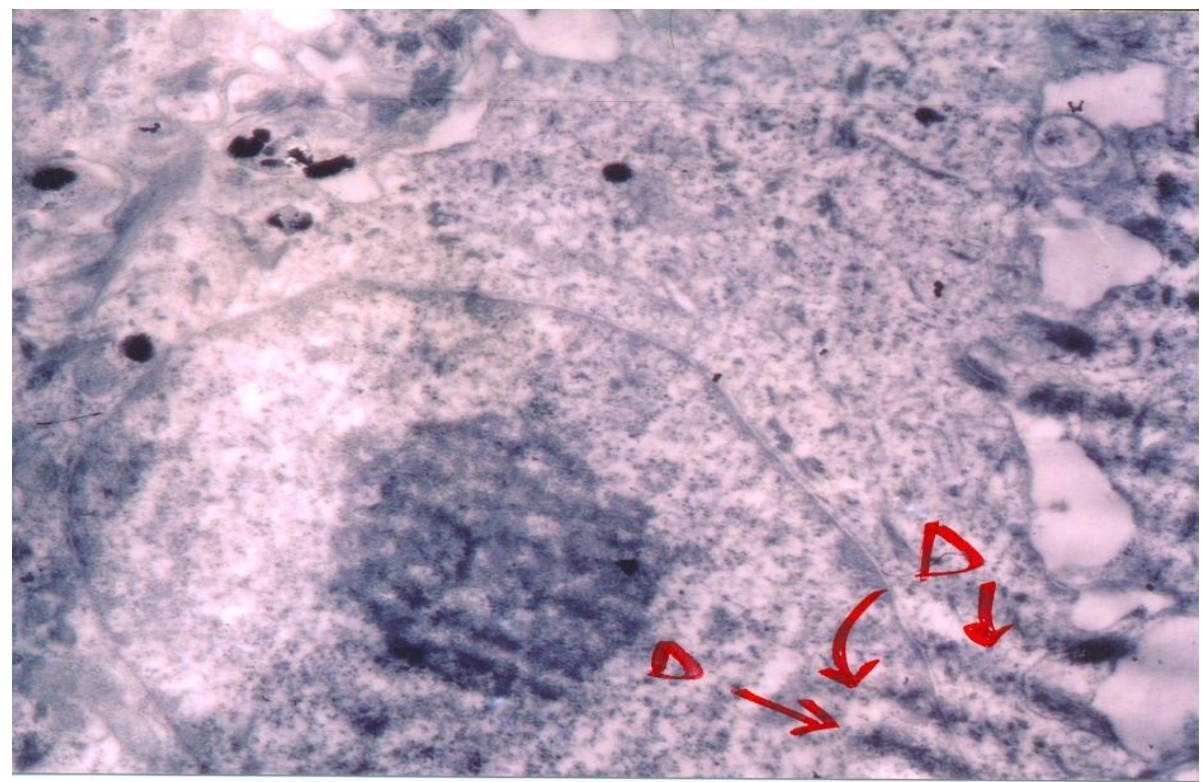

Figure 4: E.M of a case of normal skin showing normal desmosomes located in the cytoplasm between 2 keratinocytes $X \mathbf{5 0 0 0}$ double stain lead acetate \& uranyl phosphate [ $\mathrm{D}=$ desmosome].

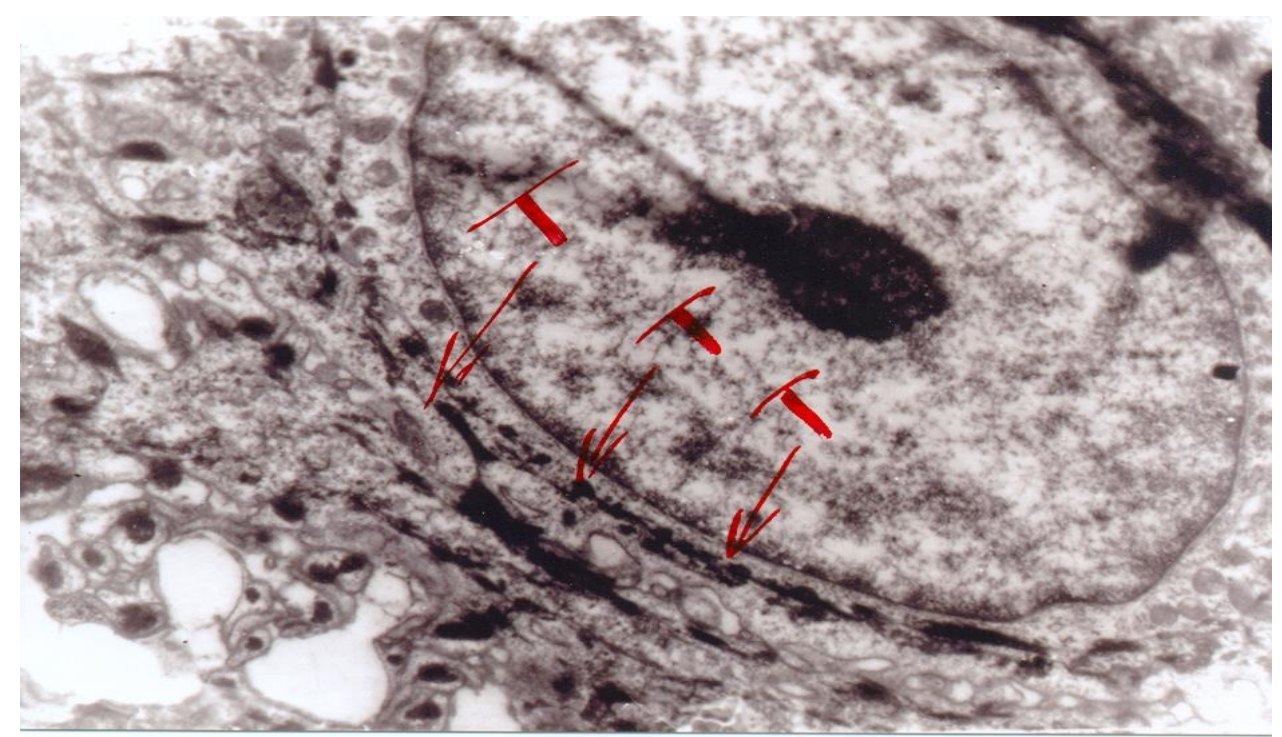

Figure 5: E.M of a case of normal skin showing normal tonofilaments in the form of loose bundles of electron dense filaments X 5000 double stain lead acetate \& uranyl phosphate $[\mathrm{T}=$ tonofilament $]$. 


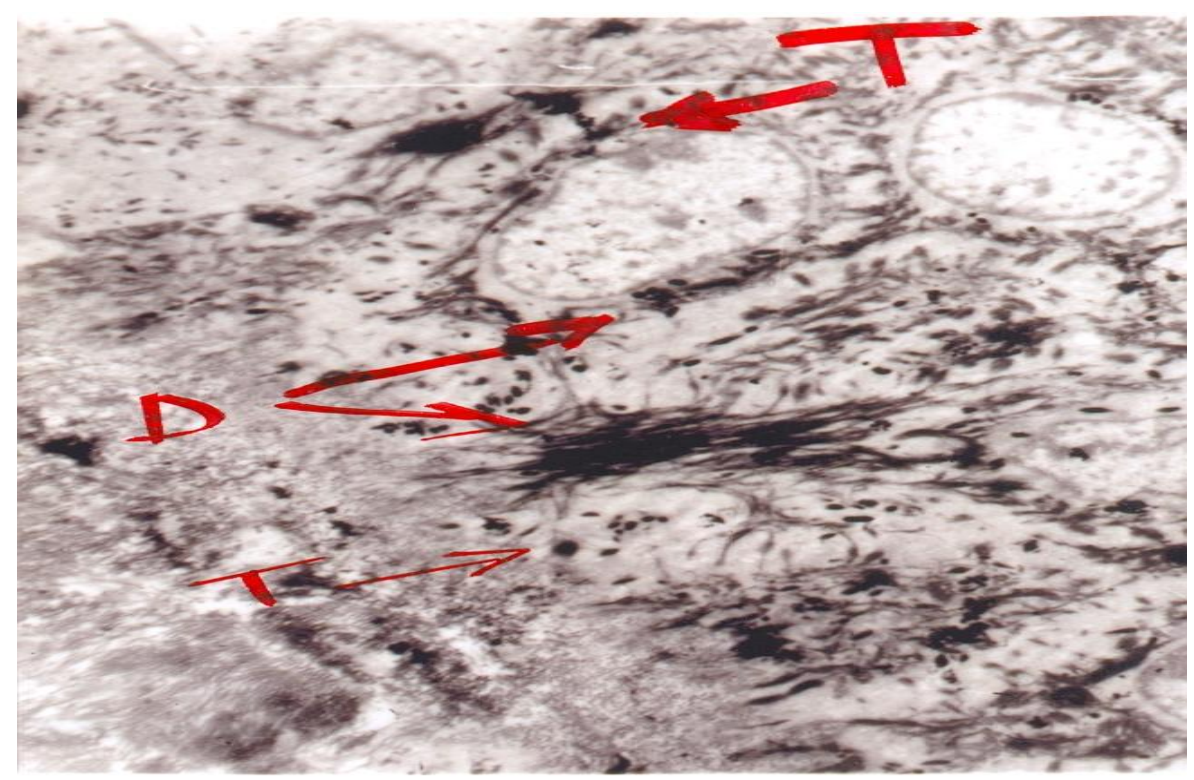

Figure 6: E.M of a case of L.P. showing marked increase in size \& number of tonofilaments \& desmosome filling about $1 / 3$ of the cytoplasm also there is a marked increase in the cytoskeletal apparatus of the cell [X 5000 double stain].

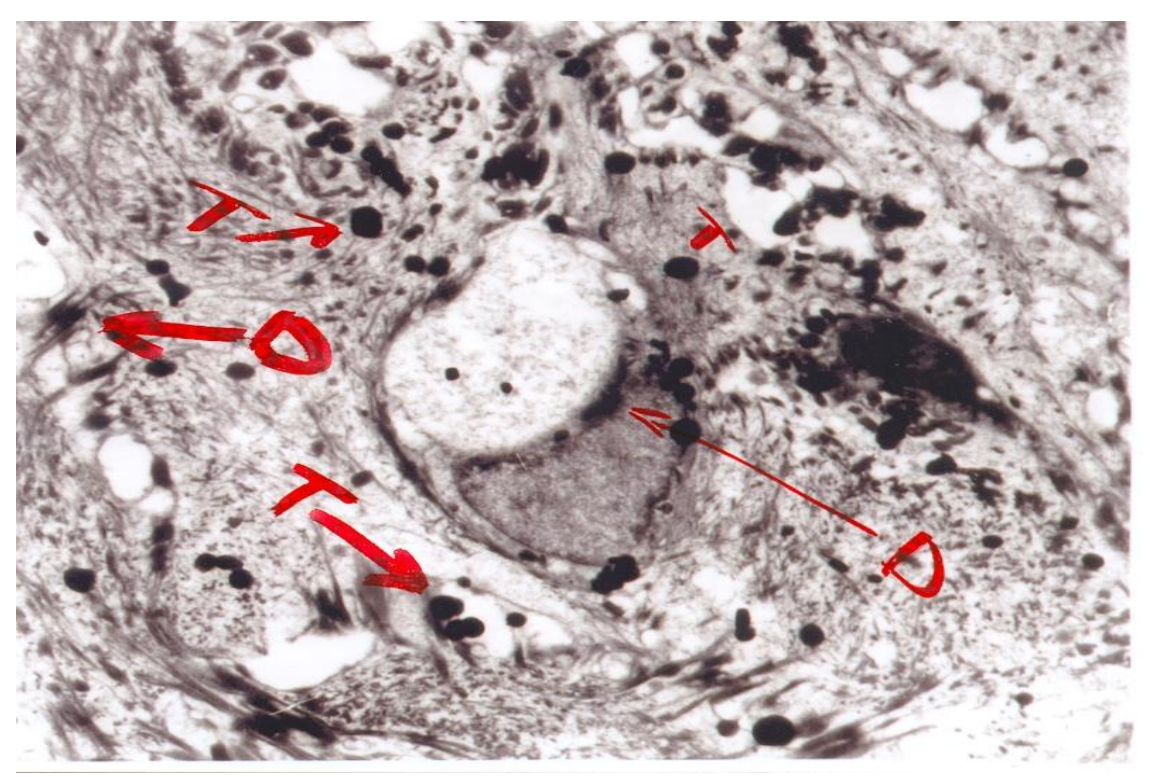

Figure 7: E.M of a case of L.P. showing marked increase of desmosome \& tonofilaments in another case [X 5000 double stain]. 


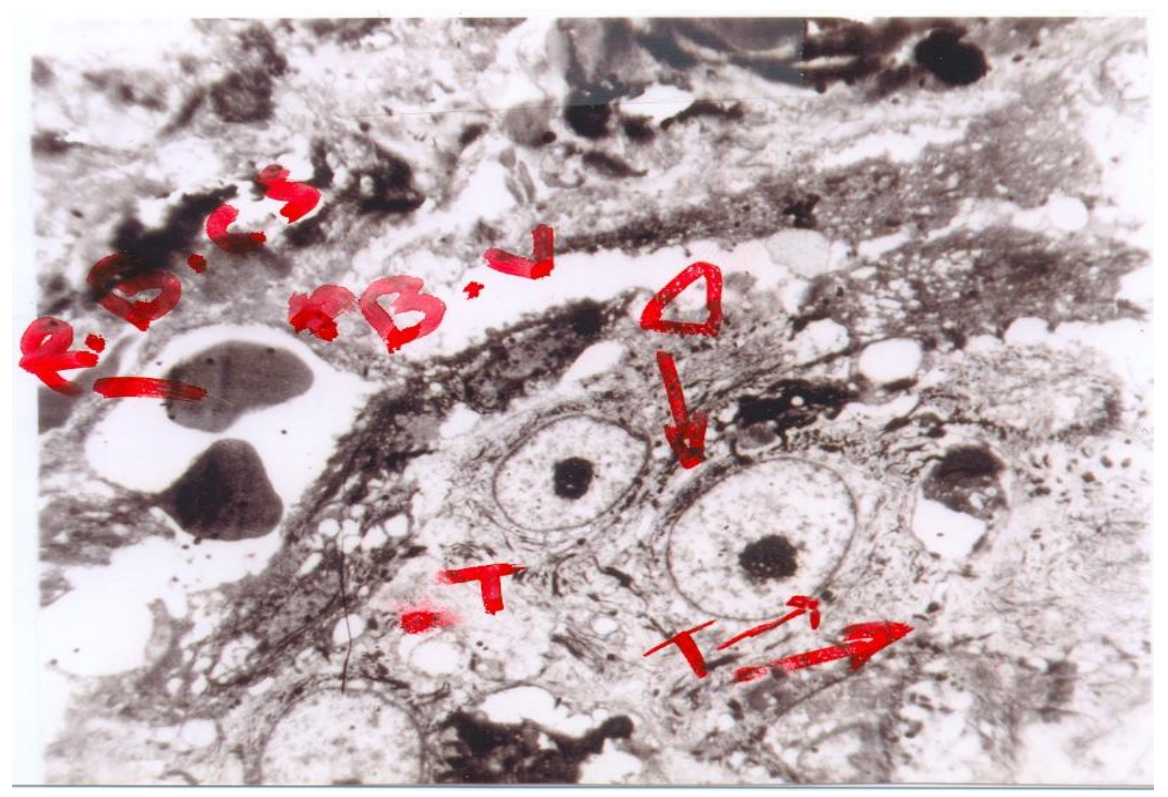

Figure 8: E.M of L.P. showing well marked tonofilaments in the keratinocytes of the epidermis also there is B.V. with 2 R.B.C.s. [B.V = blood vessel].

\section{Discussion}

Lichen planus (L.P) is an idiopathic inflammatory disease of the skin \& mucous membrane. It is characterized by pruritic violaceous papules that favor the extremities (Boyd and Neldner, 1991). There is growing body evidence that L.P represents $\mathrm{T}$ cell mediated autoimmune damage of basal keratinocytes that express altered self antigen on their surface (Shiohara and Kana, 2003). Clinical observations have long suggested a relationship between exposure to a number of exogenous agents (e.g. viruses, medications and contact allergens) and the development of L.P (Shiohara and Kana, 2003).

Desmosomes are ultrastructural particles apparently important in cellular adhesion, being particularly numerous and prominent in sites such as epidermis, where resistance to mechanical changes is essential (Carr and Tover, 1982).

Desmosomes are responsible for the adhesion of keratinocytes \& they are present throughout the epidermis but increase in size and number as keratinocytes migrate up the epidermis (Shiohara and Kana, 2003).

Ultrastructural study of desmosome reveals that desmosomes appears as a patches of large variably sized and irregular intra membranous particles. The desmosomes consist of pair of dense attachment plaques just beneath each of the two adjacent lateral cell membrane which are separated by $20 \mathrm{~nm}$ space that often has a central dense line (Weiss, 1983). Desmosomes consist of number of proteins including desmoplakin, plakoglobin \& desmosomal cadherin (Hashimoto, 2000).

Tonofilaments are major cytoskeleton structure in mammalian epidermis. They are present at all stages of differentiation from the mitotically active basal cells through the spinous and granular cell layers to the dead horny cells which desquamate from the surface of the skin (Skenow and Skenow, 1983).

In our study which included six patients proved to have L.P (4 males \& 2 females with mean age 46.2). Ultrastructure study focused in the structure \& number of both desmosome \& tonofilament revealed in all patients increase in size and number of both of them which can be explained as a defensive mechanism from the cell to increase the resistance of the cell to frequent scratching $\&$ itching which usually accompanied the disease. 
Our study coincide with the study of Ebner \& Gebhart (1976) who made a comparison of ultrastructure of both lichen nitidus \& lichen planus and they found that in both diseases there is increase in size and number of both desmosomes \& tonofilaments.

\section{References}

1- Boyd AS and Neldner KH (1991): Lichen planus. J. Am. Acad. Dermatol; 25: 593619.

2- Carr $k$ and Tover $P$ (1982): In: Cell structure. 3rd edition. Churchill Livingstone. P 71.

3- Cowin P and Burre (1996): Cytoskeletonmembrane interactions. Curr opin Cell Biol; 8: $56-65$.

4- Ebner $H$ and Gebhart W (1976): Epidermal changes in lichen planus. J. Cut. Pathol; 3: 167- 174.
5- Fimiani m, Alessandrimi A and Castelli M (1986): Ultrastructure observations in lichen nitidus. Arch. Dermatol. Res; 279: 77- 82.

6- Hashimoto K (2000): Regulation of keratinocyte function by growth factors. J. Dermatol. Sci; 24: 46- 50.

7- Nickoloff BJ, Qin JZ and Chaturvedi (2002): Jagged- 1 mediated activation of notch signaling induces complete maturation of human keratinocytes. Cell Death. Differ; 9: 842-55.

8- Pock, Bednar B and Vasmik F (1988): Electron microscopic finding in lichen planus.24:193- 200.

9- Shiohara T and Kana Y (2003): Lichen planus \& lichenoid dermatoses in: Dermatology. $1^{\text {st }}$ edition. Mosby. Page 175.

10- Skenow D and Skenow C (1983): Tonofilament differentiation in human epidermis. Exp. Cell Research, 143: 27- 35.

11- Weiss L (1983): In: Histology, cell and tissue biology. 5th edition. Mac Millan press. Page. 127. 


\title{
دراسة بالميكروسكوب الإليكترونى للايسموزوم و التونوفيلمنت فى مرضى الحزاز العصبى المنبسط لإيسوم
}

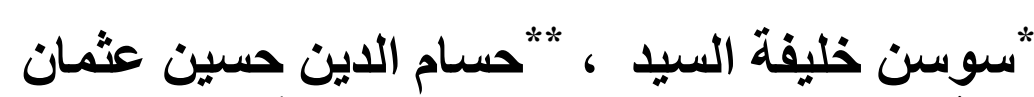

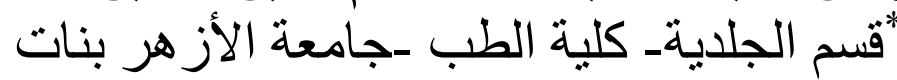 \\ *** قسم التشريح- كلية الطب- جامعة الأز هر بنين الطن بنات
}

الحزاز من الأمر اض الجلدية غير معروفة السبب التى تصيب الجلد و الأغشية

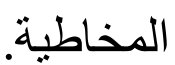

الديسموزوم من المركبات المسئولة عن ربط خلايا الجلد سويا.

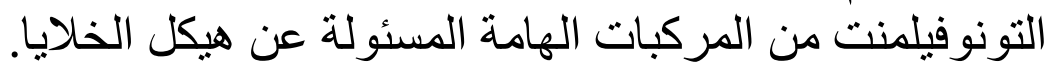

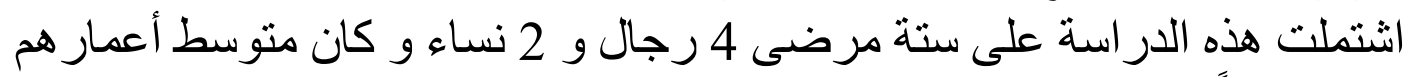

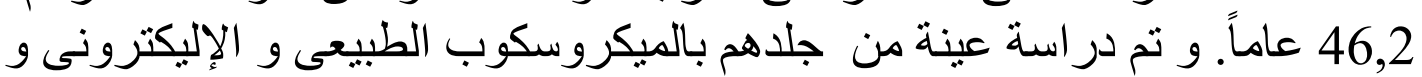

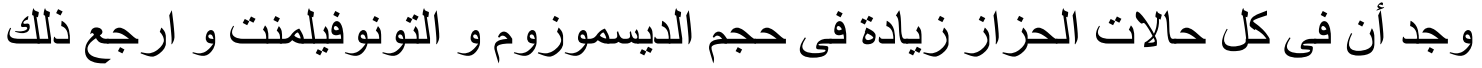

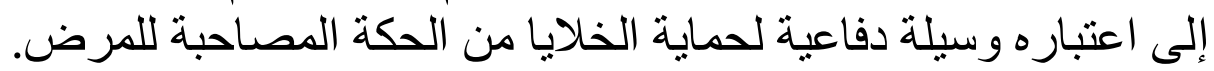

